\title{
Determinants of Rural Farmers' Adoption of Climate Change Adaptation Strategies: Evidence from the Amathole District Municipality, Eastern Cape Province, South Africa
}

\author{
A. Taruvinga, M. Visser, and L. Zhou
}

\begin{abstract}
There is consensus that rural farmers' livelihoods are vulnerable to climate change. Also, literature suggests that locally driven adaptations are critical complementary strategies that can be targeted to reduce the negative effects of climate change in the short-run. Thus far, through using a cross sectional survey sample of 200 rural farmers from the Amathole district municipality of the Eastern Cape Province of South Africa, the paper estimated farmers' climate change adaptation strategies, adaptation portfolio diversity and factors that condition farmers' adoption behavior. The results reveal several crop, livestock and non-farm based adaptation strategies skewed in favour of crop and non-farm floral based techniques. The results further indicate that rural farmers in general are low adopters of climate change adaptation strategies with poor adaptation portfolio diversity. Regression estimates reveal several socio-economic and institutional factors as drivers of adoption and adaptation portfolio diversity worth targeting to promote the ability of rural farmers to cope with climate change.
\end{abstract}

Index Terms - Climate change, adaptation strategies.

\section{INTRODUCTION}

The generic view when it comes to the rural sector in Africa is that of a region driven by agriculture [1] and several natural resource-based non-farm and off-farm livelihood activities [2]. Against this background, in response to climate change, rural communities have managed to align their livelihood strategies in various available livelihood portfolios, hoping to spread and minimize the risk associated with climate change.

This has created interesting rural resilience strategies in response to climate change [3], [4] which are worth understanding, given that farmer driven adaptations may be more sustainable for Africa than sponsored external mitigations [5], [6]. Thus far, growing research is therefore seeking to understand the drivers of climate change adaptation and mitigation strategies among farmers [7]-[9]. This is mainly motivated by the fact that adaptation strategies and farmer responses to climate change are heterogeneous, depending on region [10], the socio-economic attributes of

Manuscript received September 18, 2015; revised November 13, 2015.

A. Taruvinga is with the Department of Agricultural Economics and Extension, University of Fort Hare, Bag X1314, Alice 5700, South Africa (e-mail: ataruvinga@ufh.ac.za).

M. Visser is with the School of Economics, University of Cape Town, Private Bag X3, Rondebosch, Cape Town, 7701, South Africa (e-mail: martine.visser@uct.ac.za).

L. Zhou is with the Risk and Vulnerability Science Centre, Climatic Change/Action, Food and Water Security, University of Fort Hare, Bag X1314, Alice 5700, South Africa (e-mail: lzhou@ufh.ac.za). farmers [11] and existing institutional support and infrastructure [12]. This study was therefore undertaken to identify various crop, livestock, non-farm fauna and non-farm floral based climate change adaptation techniques implemented by rural farmers and important factors affecting their implementation behaviors.

\section{OBJECTIVES}

- To assess rural farmers' adaptation strategies to climate change.

- To estimate factors that influence rural farmers' implementation of climate change adaptation strategies.

\section{LITERATURE REVIEW}

This section presents literature on adaptation strategies to climate change and factors that influence adaptations. The following adaptation strategies are reported in literature: changing crop varieties, intercropping, staggering planting dates, integration of on-farm and off-farm livelihoods activities, supplementary irrigation, use of water conservation techniques/water harvesting [6], agro-forestry, use of compost and fertilizers, destocking, fallowing [13], shifting cultivation, crop-livestock and livestock-crop switching, shading and shelter, use of insurance and use of livestock species that are more suited to drier conditions [4]-[15].

Literature also suggests that adaptation in general is conditioned by several socio-economic (gender, education, family size, age), institutional (access to extension, credit, markets) and location (temperature and rainfall) factors [4]-[17]. A few studies also report "no adaptation" as an adaptation strategy [4]-[18], yet such scenarios are very popular which suggests the desperate nature often faced by rural households when exposed to climate change and variability shocks.

\section{Methodology}

The study was conducted inthe Amathole District Municipality of the Eastern Cape Province of South Africa, using cross sectional survey data $(N=200)$.

\section{A. Theoretical Framework}

Rural farmers reside in different geographical locations across Africa. They also have different socio-economic and institutional attributes. These three conditions (geographical location, socio-economic and institutional attributes) 
influence their selection choices of adaptation strategies to climate change [5]-[18] based on the utility associated with each choice [13].

Thus far, the utility associated with each choice by the $i^{\text {th }}$ rural farmer is not directly observable, while the adaptation choices made are observable, and unordered thus suggesting that an adaptation strategy to climate change may be explained by the random utility maximization theory [13]-[18]. A rural farmer from the Amathole District Municipality of the Eastern Cape Province of South Africa would therefore choose adaptation strategy $j$ over adaptation strategy " $k$ " if, and only if,the perceived utility from adaptation strategy " $j$ " is greater than that of " $k$ ", as illustra , [19].

$$
U_{i j}\left(\grave{\beta_{j}} X_{i}+\varepsilon_{j}\right)>\left(U_{i k}\left(\hat{\beta_{k}} X_{i}+\varepsilon_{i}\right)\right), \forall k \neq j
$$

where:

- $U_{j k}=$ denotes perceived utilities of adaptation strategies “ $j$ " and " $k$ "

- $X_{i}=$ vector of explanatory variables that condition the perceived adaptation strategy

- $\beta_{j k}=$ parameters to be estimated

- $e_{i k}=$ error terms (assumed to be independently and identically distributed)

Using econometric models it becomes possible to relate observable socio-economic, institutional and climate variables to adaptation selection choices made by rural $i^{\text {th }}$ farmer from the Amathole District Municipality.

Several econometric models have been used to estimate the relationship between farmers' identified adaptation strategies and a set of predictor independent variables. They range from univariate techniques, multivariate techniques to multinomial discrete choice models [6]-[20]. However, if a variable is measured by counting, which is the case in this paper; it is treated as a continuous variable [21]. Generalised linear regression models would therefore best represent the dependent variable. The Poisson count regression model (PCRM), negative binomial model and simple linear regression (OLS) can be used. The first two models have strict requirements that give them operational problems as follows: for the Poisson distribution, it assumes that the mean and variance of the dependent variable(s) are equal, but normally as a result of over-dispersion; the conditional variance of the dependent variable exceeds the conditional mean [22].

A simple linear regression model was developed to identify factors affecting rural farmers' implementation (adoption) of climate change adaptation techniques. Frequency of use of various climate change adaptation techniques across a range of adaptation portfolios - that is, count of adaptation techniques implemented by rural farmers was treated as the dependent variable in the first equation. In the second equation the frequency of adaptation portfolios used by farmers - thus, count of adaptation portfolios used, was treated as the dependent variable. The analysis considered setting simple linear regression equations to estimate the reduced form models of rural farmers' climate change adaptation strategies, as illustrated in equation 2 .

$$
Y_{j}=\beta_{0}+\beta_{i} X_{i}+u
$$

where:

$\mathrm{y}_{j}=$ the dependent variable representing count of adaptation techniques implemented in equation 1 and count of adaptation portfolios used in equation 2, explained by,

$b_{i}=$ the vector of parameters and

$X_{i}=$ the vector of exogenous explanatory variables with

$b_{0}=$ the constant term and

$u=$ the error term.

\section{RESULTS AND DISCUSSION}

This section presents the results and discussion of the study. Rural farmers' adaptation strategies and adaptation portfolios to climate change are presented as summarized in Fig. 1, Fig. 2, Fig. 3 and Table I, followed by factors that influence adoption and adaptation portfolio diversity (Table II).

\section{A. Rural Farmers' Adaptation Strategies to Climate Change}

Fig. 1 presents a summary of the reported adaptation strategies to climate change from the study area. Results indicate that with respect to climate change from a crop husbandry point of view, a majority of rural farmers resort to: changing crop varieties (77\%), intercropping (69\%), staggering planting dates $(69 \%)$, supplementary irrigation $(62 \%)$, use of compost and fertilizer $(80 \%)$ and shifting cultivation $(60 \%)$. Similar comparable results are reported in literature [6]-[13]. To enhance these strategies access, size and ownership of arable land may be an important factor.

Available livestock coping strategies, though very limited and practiced by only a few farmers, include: destocking (18\%) and crop-livestock switching (5\%). Previous literature reports similar adaptations [4]-[15]. Non-farm floral adaptation strategies include: use of indigenous leaf vegetables $(71 \%)$, use of indigenous fruits $(63 \%)$, indigenous timber (35\%) and selling fire wood (26\%). Non-farm fauna adaptation strategies includes: hunting mammals (18\%) and bird shooting (17\%). Recent studies suggest the emerging importance of indigenous foods towards supplementing household food security, dietary diversity and dietary quality [23], [24].

These findings suggest an overreliance on crop based adaptations at the expense of other portfolio activities, thus, poor adaptation portfolio diversity for rural farmers. This observation may suggest barriers to entry to these other portfolio activities worth understanding in order to improve adaptation options for rural farmers. In the next section, the paper compares the share of different adaptation portfolios available to rural farmers.

Fig. 2 summarizes the share of various climate change adaptation portfolios. Results reveal that crop based adaptations have the highest share $(61 \%)$ followed by non-farm floral based adaptations (25\%), non-farm fauna strategies (5\%), other adaptations (6\%) and, lastly, livestock based adaptations (3\%).

Two messages are suggested by these results. Firstly, the results suggest that rural farmers from the study area may have mastered more crop husbandry and non-farm floral adaptation strategies, possibly as a result of the availability of such activities and easy entry. To avoid a scramble fornatural 
floral resources as a result of the emerging interests of rural farmers to use them as a climate change safety net, more research, investment and policy may be required to guide sustainable harvesting and boost availability in the face of potential overuse.

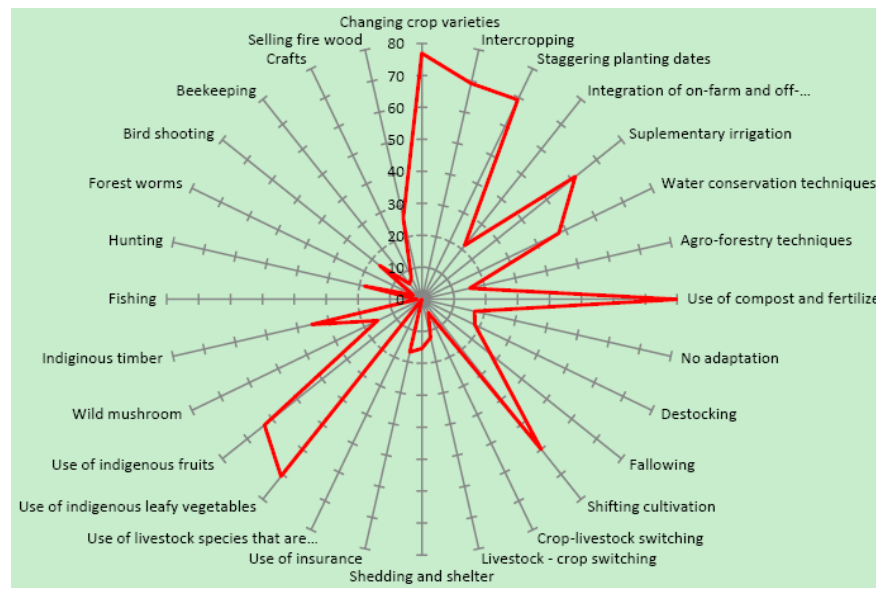

Fig. 1. Reported rural farmers' adaptation strategies to climate change.

Secondly, livestock and non-farm fauna adaptation strategies are very limited in terms of the activities that farmers can pursue and their willingness to adopt them. These observations suggest possible limitations and barriers to entry worth understanding to promote a wider climate change adaptation selection pool for rural farmers.

The next section uncovers climate change adaptation diversification based on the count of adaptation strategies adopted by farmers.

\section{B. Rural farmers' Adaptation Diversity across Portfolios}

Table I and Fig. 3 present the observed climate change adaptation diversity from the study area. Results indicate that, on average, $62.5 \%$ of the respondents were classified in the low adopter category, $37 \%$ in the medium adopter category and $0.5 \%$ in the high adopter category with a mean frequency of 9 adaptations per farmer.

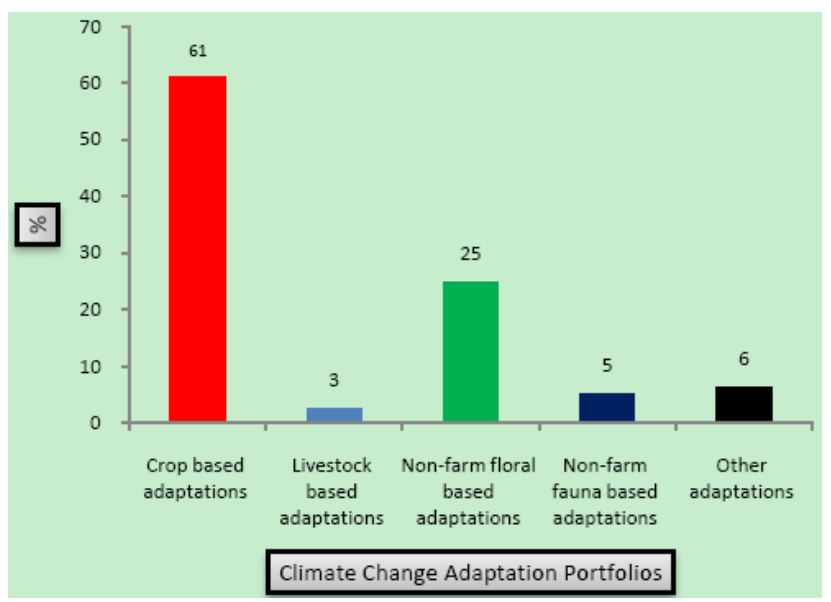

Fig. 2. Climate change adaptation portfolios.

TABLE I: COUNT OF ADAPTATION TECHNIQUES IMPLEMENTED BY FARMERS

\begin{tabular}{|c|c|c|}
\hline \multicolumn{3}{|c|}{ Count of adaptation techniques implemented } \\
\hline $0-10$ counts & $11-20$ counts & $>20$ counts \\
\hline \multicolumn{3}{|c|}{} \\
\hline $62.5 \%$ & $37 \%$ & $0.5 \%$ \\
\hline Low adopters & Average adopters & High adopters \\
\hline
\end{tabular}

Besides the frequency of adaptations, the diversity of adaptation portfolios is also critical because if all of the adaptations are derived from one portfolio, like crop husbandry, in the event of bad weather, most of the adaptations will be adversely affected. Thus far, the observed dominance of the respondents in the low adopter category is seriously affected by their poor adaptation portfolio diversity, as summarized in Fig. 2 (above half of their adaptations defined in one portfolio $-61 \%$ crop based adaptations).

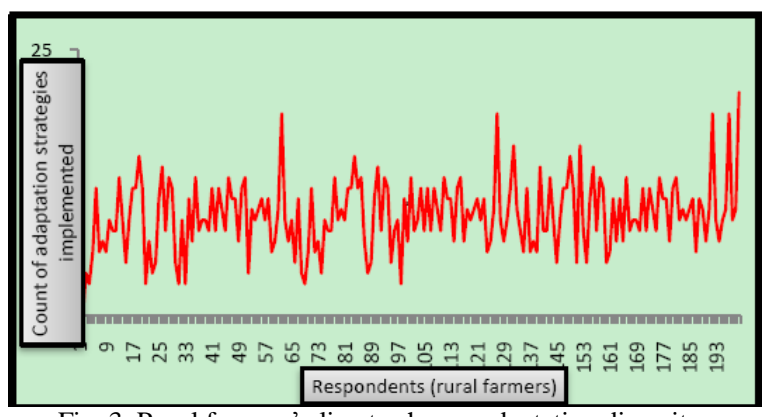

Fig. 3. Rural farmers' climate change adaptation diversity.

These findings reveal low adaptation capacity for rural farmers, possibly as a result of limited adaptation options, barriers to entry and overreliance on crop husbandry activities. This scenario presents rural farmers who are very vulnerable to climate change effects, faced with limited adaptation options which are confined in one adaptation portfolio. For the purpose of understanding drivers of climate change adaptation strategies, in the next section, the paper estimates the determinants of adaptation strategies among rural farmers.

\section{Factors that Influence Adoption Frequency and Adaptation Portfolio Diversity}

In this section, the paper estimated factors that influence rural farmers' adoption frequency and the adaptation portfolio diversity of climate change adaptation strategies. Table 2presents linear regression estimates for determinants of adoption frequency and adaptation portfolio diversity. With reference to the overall fit of the models, the obtained $\mathrm{R}^{2}$ (0.791: 0.541) suggests that the weighted combination of predictor variables was jointly significant in explaining each of the dependent variables.

The results reveal that a one standard deviation positive change in the age of rural farmers, holding other predictor variables constant, yields an increase of 0.48 standard deviations for adopting climate change adaptation strategies. These results suggest that age positively conditions the probability of farmers to adopt climate change adaptation strategies [25], possibly as a result of earned experience [26], broad social networks and accumulation of wealth.

As expected, a one standard deviation positive change in the level of education holding other predictor variables constant increases adoption frequency and adaptation portfolio diversity by 1.43 and 0.260 standard deviations respectively. These findings suggest that education positively influences rural farmers' ability to adopt more climate change adaptation strategies and their ability to spread adaptation strategies across various adaptation portfolios. This may be explained by a high level of awareness (general appreciation of benefits of adapting to climate change) and access to adaptation information common with educated 
farmers. Similar comparable observations were noted by several authors [14]-[29].

TABLE II: FACTORS THAT INFLUENCE AdOPTION FREQUENCY AND ADAPTATION PORTFOLIO DiVERSITY OF CLIMATE CHANGE ADAPTATION STRATEGIES

\begin{tabular}{|c|c|c|c|c|c|c|}
\hline \multirow[t]{2}{*}{ Variables } & \multicolumn{3}{|c|}{$\begin{array}{l}\text { Adoption frequency (count of adaptation } \\
\text { strategies implemented across portfolios) }\end{array}$} & \multicolumn{3}{|c|}{$\begin{array}{l}\text { Adaptation portfolio diversity (count of } \\
\text { adaptation portfolios implemented) }\end{array}$} \\
\hline & $B$ & Std. E & $t$ & $B$ & Std. $E$ & $t$ \\
\hline (Constant) & 1.261 & 1.097 & 1.150 & 1.912 & .376 & $5.087 * *$ \\
\hline 1) Age & .048 & .015 & $3.249^{*}$ & .006 & .005 & 1.166 \\
\hline 2) Gender & .540 & .483 & 1.116 & .180 & .176 & 1.024 \\
\hline 3) Education & 1.430 & .337 & $4.238^{* *}$ & .260 & .124 & $2.097 *$ \\
\hline 4) Family Size & -.247 & .112 & $-2.202 *$ & -.143 & .041 & $-3.477^{*}$ \\
\hline 5) Wealth Status & 2.180 & .603 & $3.614^{*}$ & .017 & .219 & .079 \\
\hline 6) Land Ownership & 2.569 & .620 & $4.143 * *$ & .017 & .219 & $2.068^{*}$ \\
\hline 7) Land Size & .148 & .310 & .478 & .148 & .113 & 1.304 \\
\hline 8) Access to formal credit & .445 & .777 & .573 & .724 & .286 & $2.532 *$ \\
\hline 9) Access to informal credit & .682 & .554 & 1.230 & .458 & .204 & $2.248^{*}$ \\
\hline 10) Membership to CBOs & -.016 & .599 & -.027 & .121 & .215 & .564 \\
\hline 11) Access to extension & .669 & .527 & 1.270 & .409 & .193 & $2.117^{*}$ \\
\hline a) No. of observations & & & 200 & & & 200 \\
\hline b) F. & & & 18.199 & & & 6.353 \\
\hline c) Sig. F. & & & .000 & & & .000 \\
\hline d) $R^{2}$ & & & .791 & & & .541 \\
\hline
\end{tabular}

Notes: $* *$ and $*$ indicate significance at 0.01 and 0.05 probability level, respectively.

For a one standard deviation positive change in family size holding other predictor variables constant, the results reveal a decrease in both adoption and adaptation portfolio diversity by 0.427 and 0.143 standard deviations respectively. The observed results suggest that larger family size negatively conditions the ability of rural farmers to adopt and spread climate change adaptation strategies. Similar negative influences of household size on adaptation to climate change are also shared in literature [27]-[30]. Adoption costs may hinder larger households who normally focus their resources on sustaining immediate family members' needs at the expense of adaptation strategies. The assumed potential of large families to diversify their labor force into other non-farming activities [31], hence improving adaptation portfolio diversity, may be limited in rural areas where off-farm opportunities are poorly defined and very limited [4].

A one standard deviation positive change in the level of wealth status of rural farmers holding other predictor variables constant, increases adoption by 2.180 standard deviations. The observed positive effect may be a result of the ability to finance adaptation techniques like supplementary irrigation that involves high initial injection and operational capital, use of fertilizers and changing crop varieties.

Land ownership also explains rural farmers' adoption and adaptation portfolio diversity, where a one standard deviation positive change in land ownership holding other things constant increases adoption and adaptation portfolio diversity by 2.569 and 0.017 standard deviations respectively. Descriptive results reveal overreliance on crop based adaptations from the study area that require ownership of land. Thus far, the observed positive correlation uncovers the importance of land for promotion of crop and livestock based adaptations and, possibly, other non-farm land based adaptation activities like harvesting indigenous leafy vegetables and indigenous fruits.

Both, access to formal and informal credit to finance adaptation activities positively explain adaptation portfolio diversity. The results reveal that a one standard deviation positive change in access to either formal or informal credit will increase adaptation portfolio diversity by 0.286 and 0.204 standard deviations, respectively. The availability of credit gives rural farmers several options to finance adaptation strategies like supplementary irrigation, improved hybrids and fertilizer applications. Similar positive effects are also reported in literature [25]-[32].

Lastly, the results further indicate that access to extension services by rural farmers positively conditions their ability to spread their climate change adaptation strategies across various adaptation portfolios. Previously [4], it was argued that access to information about climate change forecasting and adaptation options remain a crucial factor which contributes promotes farmers' use of various adaptation strategies.

\section{CONCLUSION}

The paper concludes that with reference to climate change adaptations, rural farmers primarily rely on crop (changing crop varieties, intercropping, staggering planting dates, supplementary irrigation, use of compost and fertilizer, shifting cultivation) and non-farm floral adaptations (use of indigenous leafy vegetables, use of indigenous fruits, use of 
indigenous timber) seriously affecting their adoption and adaptation portfolio diversity. The paper also concludes that the ability of rural farmers to adapt is conditioned by socio-economic (age, household size, education, wealth status and land ownership) and institutional (access to credit and extension) factors.

\section{POLICY INSIGHTS}

To enhance rural farmers' awareness and adoption of climate change adaptation techniques, more focus should therefore be given to socio-economic (age, education, household size, wealth, land ownership) factors as suggested by model results. For the purpose of promoting rural farmers' ability to spread their adaptation techniques across a range of adaptation portfolios, the following institutional factors should be targeted as suggested by model results (access to formal and informal credit and extension services). Public policy that creates a supportive rural institutional framework and promotes rural education, rural income initiatives and climate change awareness campaigns may promote the ability of rural farmers to adapt.

\section{ACKNOWLEDGMENT}

This research was supported by funding from the Department for International Development (DfID) under the Climate Impact Research Capacity and Leadership Enhancement (CIRCLE) programme, as well as theGovern Mbeki Research Development Centre (GMRDC) at the University of Fort Hare (UFH).

\section{REFERENCES}

[1] B. Senadza, "Nonfarm income diversification in rural Ghana: Patterns and determinants," African Development Review, vol. 24, no. 3, pp 233-244, 2012

[2] S. Ndhleve, L. Musemwa, and L. Zhou, "Household food security in a coastal rural community of South Africa: Status, causes and coping strategies," Journal of Agricultural Biotechnology and Sustainable Development, vol. 4, no. 5. pp. 68 -74. 2012.

[3] J. F. Morton, "The impact of climate change on smallholder and subsistence agriculture," PNAS, vol. 104, no. 50, pp. 19680-19685, 2007.

[4] R. Hassan and C. Nhemachena, "Determinants of African farmers' strategies for adapting to climate change: Multinomial choice analysis," AfJARE, vol. 2, no. 1, pp. 83-104, 2008

[5] A. Taruvinga, V. Muchenje, and A. Mushunje, "Climate change impacts and adaptations on small-scale livestock production," International Journal of Development and Sustainability, vol. 2, no. 2, pp. 664-685. 2013.

[6] C. Nhemachena, R. Hassan, and J. Chakwizira, "Analysis of determinants of farm-level adaptation measures to climate change in Southern Africa," Journal of Development and Agricultural Economics, vol. 6, no. 5, pp. 232-241, 2014.

[7] A. Barnes and L. Toma, "A typology of dairy farmer perceptions towards climate change," Climate. Change, vol. 112, pp. 507-522, 2012.

[8] J. G. Arbuckle, L. W. Morton, and J. Hobbs, "Farmer beliefs and concerns about climate change and attitudes toward adaptation and mitigation," Climate Change, vol. 118, pp. 551-563, 2013.

[9] S. A. Wood, A. S. Jina, M. Jain, P. Kristjanson, and R. S. DeFries, "Smallholder farmer cropping decisions related to climate variability across multiple regions," Global Environ. Change, vol. 25, pp. 163-172, 2014.

[10] P. M. Berry, M. D. A. Rounsevell, P. A. Harrison, and E. Audsley, "Assessing the vulnerability of agricultural land use and species to climate change and the role of policy in facilitating adaptation," Environ. Sci. Policy, vol. 9, pp. 189-204, 2006.

[11] W. Adger, S. Dessai, M. Goulden, M. Hulme, I. Lorenzoni, D. Nelson, L. Naess, J. Wolf, and A. Wreford, "Are there social limits to adaptation to climate change?" Climate. Change, vol. 93, pp. 335-354, 2009.

[12] M. T. Niles, M. Lubell, and M. Brown, "How limiting factors drive agricultural adaptation to climate change," Agriculture, Ecosystems and Environment, vol. 200, pp. 178-185, 2015.

[13] F. N. Mabe, G. Sienso, and S. Donkoh, "Determinants of Choice of Climate Change AdaptationStrategies in Northern Ghana," Research in Applied Economics, vol. 6, no. 4, pp. 75-94, 2014.

[14] D. Maddison, The Perception and Adaptation to Climate Change in Africa, CEEPa Discussion Paper No. 10 Special Series on Climate Change and Agriculture in Africa, 2006.

[15] C. Nhemachena and R. Hassan, Micro-Level Analysis of Farmers' Adaptation to Climate Change in Southern Africa, Intl Food Policy Res Inst, Washington, D.C., 2007.

[16] T. T. Deressa, Measuring the Economic Impact of Climate Change on Ethiopian Agriculture: Ricardian Approach, World Bank Policy Research Paper No. 4342,World Bank, Washington, D.C., 2007.

[17] E. Bryan, C. Ringler, B. Okoba, C. Roncoli, S. Silvestri, and M. Herrero, "Adapting agriculture to climate change in Kenya: household strategies and determinants," J. Environ. Manage, vol. 114, pp. 26-35, 2013.

[18] T. T. Deressa, R. M. Hassan, C. Ringler, T. Alemu, and M. Yesuf, Analysis of the Determinants of Farmers' choice of Adaptation Methods and Perceptions of Climate Change in the Nile Basin of Ethiopia, International Food Policy Research Institute, Washington, D.C., 2008.

[19] D. S. Falco, M. Yesuf, and G. Kohlin, What Adaptation to Climate Change? Evidence from the Nile Basin, Ethiopia, International Food Policy Research Institute, 2007.

[20] N. Seo and R. Mendelsohn, Climate Change Adaptation in Africa: A Microeconomic Analysis of Livestock Choice, CEEPA Discussion Paper No. 19. Centre for Environmental Economics and Policy in Africa, University of Pretoria, 2006.

[21] J. Ali, "Factors influencing adoption of postharvest practices in vegetables," International Journal of Vegetables Science, vol. 18. pp. 29-40, 2012

[22] S. Gurmu, "Tests for detecting overdispersion in the positive Poisson regression model," J. Bus. Econ. Stat., vol. 9, no. 2, pp. 215-222, 1991.

[23] S. Mavengahama, "The contribution of indigenous vegetables to food security and nutrition within selected sites in South Africa," Ph.D. dissertation, Stellenbosch University, Stellenbosch, Western Cape, South Africa, 2013.

[24] A. Taruvinga and A. Nengovhela, "Consumers' perceptions and consumption dynamics of African Leafy Vegetables (ALVs): Evidence from Feni communal area, Eastern Cape Province, South Africa," International Proceedings of Chemical, Biological and Environmental Engineering (IPCBEE), Florence, 2015, pp. 89-95.

[25] G. A. Gbetibouo, Understanding Farmers' Perceptions and Adaptations to climate change and Variability., International Food Policy Research Institute, Washington, D.C., 2009.

[26] T. T. Deressa, R. M. Hassan, and C. Ringler, "Perception and adaptation to climate change: The case of farmers in the Nile Basin of Ethiopia," The Journal of Agricultural Science, vol. 149, pp. 23-31, 2009.

[27] T. T. Deressa, R. M. Hassan, C. Ringler, T. Alemu, and M. Yesuf, "Determinants of Farmers' choice of adaptation methods to Climate change in the Nile Basin of Ethiopia," Global Environmental Change, vol. 19 , pp. $248-255,2009$.

[28] A. E. D. Jonge, Farmers' Perception on Adaptation to Climate Change: A Case Study of Irrigators in the River Land, South Australia, Wageningen University, The Netherlands, 2010.

[29] N. O. Anyoha1, F. N. Nnadi1, J. Chikaire, J. A. Echetama, C. O. Utazi, and R. A. Ihenacho, "Socio-economic factors influencing climate change adaptation among crop farmers in Umuahia South Area of Abia State, Nigeria," Net Journal of Agricultural Science, vol. 1, no. 2, pp. 42-47, 2013

[30] T. G. Apata, K. D. Samuel, and A. O. Adeola, Analysis of Climate Change Perception and Adaptation among Arable Food Crop Farmers in South Western Nigeria, Federal Department of Agricultura Economics and Extension Services, University of Technology, Ondo State, Nigeria, 2009.

[31] R. Mano and C. Nhemachena, Assessment of the Economic Impacts of Climate Change on Agriculture in Zimbabwe: A Ricardian Approach, CEEPA Discussion Paper No. 11, Centre for Environmental Economics and Policy in Africa, University of Pretoria, 2006.

[32] B. Y. Fosu-Mensah, P. L. G. Vlek, and A. M. Manschadi, Farmers Perceptions and Adaptation to climate Change: A Case Study of Sekyedumase District in Ghana, Centre for Development Research, University of Bonn, 2010. 


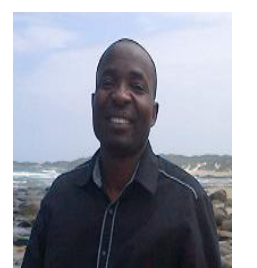

Amon Taruvinga was born in Zimbabwe. He got his B.Sc (Hons) degree in agricultural economics from University of Zimbabwe and he received his $\mathrm{PhD}$ in agricultural economics from University of Fort Hare, South Africa (2012). He is currently a lecturer in the Department of Agricultural Economics and Extension at the University of Fort Hare, South Africa and a CIRCLE visiting fellow (CVF). He is also the platform chair for Southern Africa Climate Change \& Biodiversity Research Platform (SACC\&BRP). Dr. Taruvinga specializes in biodiversity, environmental economics, human wildlife interactions, food security, climate change and smallholder agriculture. He is interested in promoting sustainable human-wildlife interaction.

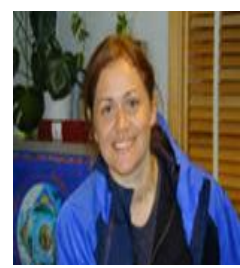

Martine Visser is a professor in the School of Economics, University of Cape Town and holds a $\mathrm{PhD}$ from Gothenburg University in Sweden. Martine is currently a research chair with the African Climate \& Development Initiative (ACDI). She is also associated with various research units within the School of Economics, include in the Environmental-Economics Policy Research Unit (EPRU), the Research Unit of Behavioral and Neuro-Economics Research (RUBEN) and the South African Labour Development Research Unit (SALDRU). Martine specializes in behavioural economic applications to climate change, natural resource use, as well as health and poverty alleviation. She is interested in how social norms and preferences such as trust, cooperation and risk aversion impact on decision making. Martine Visser mainly uses experimental methods (in the lab and in the field) combined with survey analysis and randomized control trials. Recent experimental and empirical studies have focused on cooperation and risk related to climate change, risky sexual behavior and social norms. She is also involved in several projects investigating the role of local governance and social institutions in the provision of basic services to the poor and its effects on subjective wellbeing.

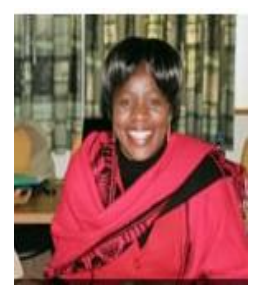

Leo Zhou is the head of the Risk and Vulnerability Science Centre (RVSC) at the University of Fort Hare, Eastern Cape, South Africa. Dr. Zhou has recently participated in the START project on climate change impact on food security among the coastal community of the Eastern Cape. Leo Zhou has produced a book chapter and documentary film for the START project, and has published papers on food security in international refereed journals. Dr Zhou is actively involved as a project steering committee member of the Eastern Cape Anti-Poverty Food Security committee. She also supervises Masters and PhD students recruited under the RVSC. 